\title{
PLURALISMO, MULTICULTURALISMO E RECONHECIMENTO UMA ANÁLISE CONSTITUCIONAL DO DIREITO DOS POVOS INDÍGENAS AO RECONHECIMENTO
}

\section{Rodrigo Mioto dos Santos}

Graduado em Direito pela Universidade Estadual de Londrina e Mestrando em Filosofia e Teoria do Direito pelo Curso de Pós-Graduação em Direito da Universidade Federal de Santa Catarina. Bolsista da CAPES. A primeira versão deste artigo, um tanto quanto maior do que esta, foi apresentada como requisito para a aprovação na disciplina "Pluralismo Jurídico", ministrada pelo Prof. Dr. Antônio Carlos Wolkmer, durante o terceiro trimestre de 2004.

e-mail: rodrigo.ms@pop.com.br

RESUMO: Analisa conceitos do multiculturalismo e do pluralismo jurídico. Interpreta o tratamento dado aos povos indígenas pela Constituição brasileira de 1988 e pela Convenção n.. 169 da OIT. Analisa exemplos prático-jurídicos acerca da efetivação do direito dos povos indígenas ao reconhecimento.

PALAVRAS-CHAVE: Pluralismo; Multiculturalismo; Direitos Indígenas; Reconhecimento; Convenção n. ${ }^{\circ} 169$ da OIT. 


\section{INTRODUÇÃO}

Nas preliminares de sua tese de doutorado (O Renascer dos Povos para $O$ Direito), Carlos Frederico Marés de Souza Filho (1998, pp. 6-7), relata-nos um fato extremamente significativo em uma seção intitulada "Aprendendo com os Macuxi". Conta-nos que, em meados de 1988, quando acompanhava a reunião anual dos tuxauas, onde se discutia a demarcação da terra indígena Raposa Terra do Sol. Em determinado momento da reunião um dos taxauas levantou-se e the propôs que explicasse o significado dos termos Constituição e Constituinte. Relata-nos que explicou que "a Constituição garantia direitos e limitava o poder". Ao terminar sua explicação, um dos membros da comunidade levantou-se e disse:

"Essa tal Constituição é coisa boa, está certo o que os brancos estão fazendo. Nós também temos que fazer uma Constituição para nós, para deixar escrito e sabido quem é que pode entrar em nossas terras e quem tem que ficar fora, quem é que diz onde podemos construir nossas casas e fazer nossas roças e quando são nossas festas".

Conclui Carlos Frederico Marés de Souza Filho que:

Só muitos dias depois compreendi as palavras do tuxaua. Claro, a Constituição que estávamos fazendo e que tanto trabalho nos estava dando incluir os direitos indígenas e ainda que pudesse sair, como de fato saiu, a melhor Constituição acerca dos povos indígenas de tantas quanto já regeram o Brasil, não passava de uma coisa de branco, de uma forma de expressão de um direito que continuava sendo de dominador, que continuava tentando incluir, teórica e formalmente, quem nunca fora incluído e, talvez, nem quisesse sê-lo.

A sabedoria do tuxaua macuxi era capaz de ver que o Estado e o Direito dos brancos que se pretende universal, geral e único, é parcial, especial e múltiplo. E o disse reclamando uma identidade jurídica que reflete uma prática escondida, escamoteada e não raras vezes proibida pelo nosso sistema jurídico. O tuxaua entendeu em poucos minutos o que nossa cultura constitucional não logrou compreender em 200 anos de puro estudo e reflexão: a uma sociedade que não é una, não pode corresponder um único Direito, outras formas e outras expressões haverá de existir, ainda que simuladas, dominadas, proibidas e, por tudo isto, invisíveis. 
As linhas que se seguem somente podem ser compreendidas caso o leitor tenha bem claro consigo que "a uma sociedade que não é una, não pode corresponder um único Direito".

Em que pese a relevância da questão, julgamos desnecessário apresentar um histórico do tratamento que, desde pelo menos as Grandes Navegações, tem sido dado aos povos indígenas, em especial, aos latino-americanos. Não julgamos necessário relembrar um quadro de massacre, desrespeito e dominação.

Os fenômenos da ocidentalização ou europeização e do monismo jurídico e axiológico foram, do ponto de vista simbólico, extremamente rigorosos com a cultura, a organização, as crenças, os costumes, as línguas e o direito dos povos indígenas latino-americanos. O discurso oficial esforça-se ao máximo para, se não ridicularizar, ao menos apresentar como inferior tal cultura. Esforça-se ao máximo para englobar todos num discurso que defende que só existe um caminho, uma verdade, uma luz. Um discurso que, pretendendo-se científico, mostra-se dogmático e fundamentalista.

Porém, a história sempre reaparece com a cobrança; cedo ou tarde, em maior ou menor escala, faz-se necessário prestar contas acerca da dívida histórica. E é nesse quadro de retomada das injustiças cometidas contra os povos indígenas que, nos planos político-filosófico e jurídico (para citar os dois objetos deste artigo), iniciou-se uma discussão acerca de quais direitos possuem os povos indígenas e de como se daria a efetivação de tais direitos. As teorias multiculturalistas e pluralistas, de um lado, bem como documentos legislativos importantes, de outro, têm oferecido significativas contribuições no que tange a um efetivo reconhecimento da cultura e organização dos povos indígenas, ainda que o Judiciário nem sempre esteja sensível a tais contribuições. E nesse sentido, o caso brasileiro consiste em singular exemplo.

Com efeito, como se pretende defender ao longo deste artigo, as linhasmestras do multiculturalismo e do pluralismo jurídico (e axiológico) somadas a uma corajosa e fidedigna concretização de algumas normas constitucionais, bem como de alguns dispositivos da Convenção n. ${ }^{\circ} 169$ da OIT, conferem aos povos indígenas, se não a solução de seus problemas, ao menos o reconhecimento de sua autonomia.

Assim, partindo de algumas considerações sobre as sociedades multiculturais e pluralistas dos dias presentes, e apoiado na Constituição Federal de 
1988 e na Convenção n. -169 da OIT, este artigo pretende (valendo-se, ainda, de análises empíricas) demonstrar que o direito dos povos indígenas ao pleno reconhecimento de suas culturas é, para além de necessário, algo plenamente possível.

\section{OS POVOS INDÍGENAS NUMA PERSPECTIVA MULTICULTURALISTA}

\subsection{As sociedades são multiculturais}

Dentre as obviedades que ainda precisam ser ditas, está a constatação de que hodiernamente as sociedades políticas, em esmagadora maioria, são culturalmente diversificadas. Will Kymlicka (1995, p. 13) noticia que segundo estimativas recentes, "(...) os 184 Estados independentes do mundo contêm mais de 600 grupos de línguas vivas e 5.000 grupos étnicos". Quer isso nos dizer que nossos valores, nossos princípios e nossas crenças, não passam de uma referência a mais num mundo marcado pelo fato da diversidade.

Por mais que algumas práticas e teorias desenvolvam argumentos em contrário, não se pode mais negar o fato do multiculturalismo. E é nesse contexto multicultural que surgem as minorias étnicas, ou simplesmente minorias. Dentre as várias categorias minoritárias que se pode abordar, a nós desperta particular interesse a composta pelos povos indígenas brasileiros. Interessa-nos a resposta que se deve dar à seguinte indagação: quais direitos possuem os povos indígenas brasileiros? E como veremos adiante, o multiculturalismo fornece elementos importantes na busca pela resposta a essa indagação.

\subsection{O que são as comunidades indígenas no interior de um Estado?}

Ao discorrermos sobre o multiculturalismo, faz-se necessário a elucidação prévia de alguns termos. Assim, inicialmente, cabe consignar que, na conceituação de Will Kymlicka (1995, p, 25), os povos indígenas brasileiros compõem o que podemos denominar de minorias nacionais. E isso porque, no caso das minorias nacionais, defende o autor, "a diversidade cultural surge da incorporação de culturas 
que previamente desfrutavam de autogoverno e estavam territorialmente concentradas a um Estado maior" (1995, p. 25). E complementa:

Uma das características distintivas das culturas incorporadas, as quais denomino 'minorias nacionais', é justamente o desejo de continuar sendo sociedades distintas da cultura majoritária da qual formam parte; exigem, por tanto, diversas formas de autonomia ou autogoverno para assegurar sua sobrevivência como sociedades distintas (1995, p. 25).

Resta evidente como essas definições teóricas coadunam-se perfeitamente com as comunidades indígenas que habitam - desde muito tempo - o que hoje conhecemos por território brasileiro.

Outro conceito intimamente ligado ao de minorias nacionais é o de Estados multinacionais. Segundo Kymlicka, uma fonte de diversidade cultural é a coexistência, dentro de um mesmo Estado, de mais de uma nação (uma comunidade histórica, mais ou menos completa institucionalmente, que ocupa um território ou uma terra natal determinada e que compartilha uma língua e uma cultura diferenciadas). Daí que um país que contenha dentro de seu território mais de uma nação, não poder ser considerado uma nação-Estado, "mas um Estado multinacional, onde as culturas menores compõem as 'minorias nacionais'” (1995, p.26).

Como defenderemos ao longo deste artigo, as comunidades indígenas brasileiras, em que pese o reduzido tamanho de algumas, constituem-se em verdadeiras nações dentro de nosso Estado, o que caracteriza nosso País como um Estado multinacional. Essa caracterização, contudo, está longe de configurar-se pacífica, principalmente quando a questão envolve o reconhecimento constitucional dessa diversidade.

Em verdade, não se trata de outra coisa se não de um Estado dentro de outro Estado, fato que não é difícil reconhecer. A questão que surge, no entanto, quando do reconhecimento de que há dentro de um território estatal, um outro povo, é a de saber quais direitos possuem esse povo.

\subsection{Quais direitos possuem as minorias?}

Segundo Kymlicka (1995, p. 15), após a Segunda Guerra os pensadores liberais passaram a crer que a proteção às minorias dar-se-ia simplesmente com a 
observância irrestrita dos direitos humanos (direitos e garantias fundamentais). E denuncia que, pautadas “(...) por esta filosofia, as Nações Unidas eliminaram toda referência aos direitos das minorias étnicas e nacionais de sua Declaração Universal dos Direitos Humanos". Essa visão, tipicamente liberal-individualista, ainda hoje possui grande ressonância nos discursos acadêmico e político.

Kymlicka rechaça essa concepção afirmando que "cada vez está mais claro que os direitos das minorias não podem subsumir-se sob a categoria dos direitos humanos" (1995, p. 17). Daí defender o autor que, para que se torne possível uma resolução eqüitativa das questões envolvidas no multiculturalismo, faz-se necessário "complementar os princípios tradicionais dos direitos humanos com uma teoria dos direitos das minorias" (1995, p. 18).

Em sua própria síntese, afirma o autor:

Creio, por tanto, que resulta legítimo e, de fato inevitável, complementar os direitos humanos tradicionais com os direitos das minorias. Em um Estado multicultural, uma teoria da justiça efetiva incluirá tanto direitos universais, assegurados aos indivíduos independentemente de seu pertencimento a um grupo, como determinados direitos diferenciados de grupo, ou seja, um 'status especial' para as culturas minoritárias (1995, p. 19).

Contrariamente à tese acima exposta - tipicamente liberal - de que os direitos humanos bastam às minorias, tem-se no plano fático que "em muitos países se aceita cada vez mais que algumas formas de diferença cultural somente podem acomodar-se mediante medidas legais ou constitucionais especiais, por cima - e para além - dos direitos comuns de cidadania" (KYMLICKA, 1995, pp. 46-47).

Eis, como veremos adiante, o caso dos povos indígenas no Brasil. A disposição constitucional do art. 231, caput, somada à recepção formal da Convenção 169 da OIT assegura aos índios brasileiros essa espécie de cidadania diferenciada (Íris Young), inaugurando no País uma leitura multicultural e pluralista dos direitos dos povos indígenas.

No Brasil, a forma como a questão indígena tem sido tratada pelos Governos e pela sociedade em geral torna evidente a insuficiência dos direitos e garantias fundamentais na proteção dos direitos das minorias étnicas. Aliás, trata-se efetivamente de reconhecimento étnico, nada mais apropriado do que começar pelo reconhecimento de que os direitos humanos nada mais são do que uma construção histórica européia, e de que o respeito pelas minorias étnicas exige a relativização 
desses direitos. O reconhecimento da heterogeneidade cultural exige uma revisão do caráter homogeneizante dos direitos humanos.

\section{SOBRE A NECESSIDADE DE UMA PERSPECTIVA PLURALISTA NO DIREITO}

\subsection{Do monismo ao pluralismo}

Um dos alicerces do capitalismo moderno é a crença no monismo jurídico, ou mais especificamente, a crença na idéia de que somente o Estado produz direito. É nesse sentido que Antônio Carlos Wolkmer (2001, p. 26) afirma que "(...) o fenômeno jurídico que florescerá na moderna cultura européia ocidental, a partir do século XVII e XVIII, corresponderá à visão de mundo predominante no âmbito da formação social burguesa, do modo de produção capitalista, da ideologia liberalindividualista e da centralização política, através da figura de um Estado Nacional Soberano".

Desse modo, ao fazermos uma comparação entre a precisa síntese apresentada por Wolkmer e a perspectiva multicultural acima exposta, percebemos que $\mathrm{o}$ atual contexto de multiculturalismo, pluralismo jurídico e axiológico e de resgate de propostas comunitárias e participativas não se coaduna com a proposta monista-liberal-individualista cunhada há alguns séculos, mas que tão vivamente ainda permeia o discurso oficial.

Nesse sentido, no que tange mais especificamente à produção do direito, a constatação da existência de um Estado multinacional exige um (re)pensar a questão jurídica, sobretudo no que diz respeito à sua produção e aplicação.

Dentro de um contexto de negação da alteridade, na história ocidental, "o projeto de legalidade que acaba se impondo, é aquele criado, validado e aplicado pelo próprio Estado, centralizado no exercício de sua soberania nacional" (WOLKMER, 2001, p. 45). No entanto, a insuficiência estrutural do projeto monista, historicamente não tardou a vir à tona. O advento de novos sujeitos no plano social (como os movimentos sociais) juntamente com a incapacidade do modelo formalindividualista de dar respostas às questões postas por esses novos sujeitos, preparou o terreno para a crítica pluralista. 
Essa crítica pauta-se em uma tese clara e direta:

Trata-se de extrair a constituição da normatividade não mais e apenas das fontes ou canais habituais clássicos representados pelo processo legislativo e jurisdicional do Estado, mas captar o conteúdo e a forma do fenômeno jurídico mediante a informalidade de ações concretas de atores coletivos, consensualizados pela identidade e autonomia de interesses do todo comunitário, num lócus político, independentemente dos rituais formais de institucionalização (WOLKMER, 2001, p. 119).

Ou mais especificamente, trata-se com isso de "evidenciar que, num espaço público descentralizado, marcado pela pluralidade de interesses e pela efetivação real das necessidades humanas, a juridicidade emerge das diversas formas do agir comunitário (...)" (WOLKMER, 2001, p. 119).

O direito moderno, por meio do discurso da igualdade e do discurso da cidadania, anulou as diferenças étnicas e culturais. Tentou o direito formal burguês igualar os diferentes, o que o levou a - em muitos casos - destruir a identidade de povos inteiros. Nesse sentido, o caso latino-americano é emblemático.

Disso tudo decorre a necessidade de um (re)pensar o próprio direito. Assim, o pluralismo, que segundo o prof. Antônio Carlos Wolkmer (2001, pp. 171-172) designa a "existência de mais de uma realidade, de múltiplas formas de ação prática e da diversidade de campos sociais com particularidade própria, ou seja, envolve o conjunto de fenômenos autônomos e elementos heterogêneos que não se reduzem entre si", afigura-se como um importantíssimo referencial teórico (e prático) de análise da dinâmica das minorias nacionais dentro dos chamados Estados multinacionais. Em termos mais específicos, o direito dos povos indígenas só pode ser pensando em uma perspectiva pluralista.

\section{$2.2 \quad 0$ direito dos povos indígenas}

Em que pese o contexto de unicidade, estatalidade, legalidade e monismo que caracteriza o direito moderno, a mencionada crise pela qual passa esse modelo, juntamente com o crescente processo de reivindicação de novos sujeitos coletivos, bem como a facticidade do multiculturalismo, abriram espaço, não só para a crítica, mas também para o reconhecimento, pelo próprio direito estatal, de que o fenômeno jurídico não pode pretender-se esgotar em alguns textos legais. Disso decorre que 
para além da estrutura jurídica estatal, subsiste, paralela, subjacente e concorrentemente, uma pluralidade de outras instâncias legislativas e jurisdicionais (WOLKMER, 2001, p. 286).

Quando se discute quais direitos possuem os povos indígenas, deve-se consignar como ponto-chave de discussão o fato de que os índios possuem o direito de ter direito. Faz-se necessário, pois, o reconhecimento de que os povos indígenas são sociedades complexas e auto-suficientes. E mais: possuem organização social, cultura, crenças, tradições, princípios éticos, valores e direito próprios.

Esse fato, porém, está longe de ser reconhecido pelo imaginário branco. A concepção reinante é a de que o índio e toda sua cultura são inferiores e dependentes de tutela. $\mathrm{O}$ banimento dessa mentalidade colonizadora e preconceituosa consiste em premissa basilar de uma correta compreensão acerca dos direitos indígenas. E essa necessária extinção de preconceitos deve atingir sobretudo o plano do direito. Pois é aqui, no poder regular por meio de leis a práxis social cotidiana, que de forma mais firme manifesta-se o direito de um povo à autodeterminação. E o reconhecimento desse direito passa, necessariamente, pelo reconhecimento de que tal direito é valido e paralelo ao direito estatal oficial.

É certo que isso pode gerar (e gera) problemas de harmonização entre os sistemas. Contudo, ao contrário do que o discurso dominante pretende, tal conflito nem sempre deve ser solucionado em prol do direito estatal. Nesse debate, o direito penal é o mais rico campo de análise.

Carlos Frederico Marés de Souza Filho (1998, p. 127) explica-nos que:

(...) nem sempre aquilo que é considerado crime pela lei estadual o é dentro da comunidade. E muitas vezes um ato legal para a lei é considerado crime abominável para outra cultura. Sabia-se, por exemplo, que na cultura chibcha olhar os olhos dos dirigentes era o crime mais odioso, punido com a mais dura pena. Por outro lado, em muitas sociedades indígenas não é considerada atitude criminosa tirar a vida de filho recém nascido considerado inapto para a vida social.

Essa citação permite uma boa noção da complexidade do problema. As seções que se seguem pretendem apontar alguns caminhos para a redução dessa complexidade.

Assim, entendemos que uma perspectiva pluralista é fundamental para um preciso entendimento acerca dos direitos dos povos indígenas. 


\section{A CONSTITUIÇÃO FEDERAL DE 1988 E A CONVENÇÃO 169 DA OIT: MULTICULTURALISMO E PLURALISMO NO ORDENAMENTO JURÍDICO BRASILEIRO}

\subsection{O direito ao reconhecimento na Constituição Federal de 1988}

A Constituição Federal de 1988, fruto de um - até certo ponto - amplo debate constituinte, consagrou em seu Título VIII (Da Ordem Social) um capítulo exclusivo para os índios. A existência de milhares de índios, além da significativa dívida histórica do País para com tais povos ${ }^{1}$, fez com que o Capítulo VIII (Dos Índios) do Título VIII da Constituição de 1988 dispensasse tratamento especial aos povos indígenas.

E dentro desse capítulo constitucional dedicado aos índios assume destaque o caput do art. 231, segundo o qual "São reconhecidos aos índios sua organização social, costumes, línguas, crenças e tradições, e os direitos originários sobre as terras que tradicionalmente ocupam, competindo à União demarcá-las, proteger e fazer respeitar todos os seus bens". Como teremos oportunidade de ver adiante, essa norma constitucional consiste em elemento chave para um preciso entendimento acerca dos direitos dos povos indígenas.

Segundo Carlos Frederico Marés de Souza Filho (1998, p. 112), "A Constituição de 1988 reconhece aos índios o direito de ser índio, de manter-se como índio, com sua organização social, costumes, línguas, crenças e tradições". E complementa: "A partir de 5 de outubro de 1988, o índio, no Brasil, têm o direito de ser índio".

De fato, a primeira parte do caput do art. 231 da Constituição, ao reconhecer aos índios sua organização social, seus costumes, suas línguas, crenças e tradições, criou um problema para a dogmática jurídica formalista de base liberalindividualista. E isso pelo fato de que, dentro das noções de organização social, costumes, crenças e tradições inclui-se, inegavelmente, a questão da organização jurídica (em seus sentidos administrativo, legislativo e judiciário). Desse modo, surge

Segundo dados da FUNAI, existem hoje no Brasil cerca de 345 mil índios, distribuídos entre 215 sociedades indígenas. Disponíveis em http://www.funai.gov.br/funai.htm Acesso em 07/03/2005. 
a questão de como deve ser conciliada essa organização jurídica indígena com a organização jurídica estatal.

O intérprete constitucional deve ser ousado. Deve, como a Constituição que interpreta, enxergar para além do convencional, para além da tradição, para além de um passado de formalismo, ditadura e sonegação de direitos. Daí que deva esse intérprete conferir ao art. 231, caput, da Constituição Federal de 1988 um significado condizente com as reivindicações dos povos aos quais é dirigida a disposição constitucional.

Nessa perspectiva, por mais espanto que possa causar ao status quo, dentro de um quadro de reconhecimento do princípio da autodeterminação dos povos, deve o intérprete constitucional reconhecer, concretizando assim 'a vontade constitucional', que a partir de 5 de outubro de 1988, os povos indígenas brasileiros gozam de alto grau de autonomia, devendo o Estado brasileiro assumir um papel não de tutor, mas de colaborador, trabalhando os poderes Legislativo, Executivo e principalmente - Judiciário, para que o reconhecimento aos índios de sua organização social, costumes, línguas, crenças e tradições, "abandone" o Texto Constitucional e passe a habitar a vida cotidiana das comunidades indígenas.

Nessa tarefa concretizadora, a Convenção sobre os povos indígenas e tribais em países independentes (Convenção 169 da OIT) consiste, apesar de algumas limitações injustificadas, num importante auxílio, posto que a luta indígena pelo reconhecimento de suas culturas, após 1988, passa a ser a luta pelo exercício efetivo desse reconhecimento.

\subsection{A Convenção sobre os povos indígenas e tribais em países independentes (Convenção 169 da OIT)}

Pelo Decreto Legislativo $n . \stackrel{0}{143}$, de 20 de junho de 2002, passou a integrar o sistema jurídico brasileiro à Convenção n. 169 da Organização Internacional do Trabalho sobre os povos indígenas e tribais em países independentes, documento que contribui para uma efetiva consubstancialização da norma estabalecida no art. 231, caput, da Constituição Federal.

Dentre as razões iniciais que a Convenção apresenta, destacamos o reconhecimento das "aspirações desses povos a assumir o controle de suas 
próprias instituições e formas de vida e seu desenvolvimento econômico, e manter e fortalecer suas identidades, línguas e religiões, dentro do âmbito dos Estados onde moram".

Dividida em 10 partes, a Convenção apresenta, de certa forma, um caráter ambíguo, no que diz respeito ao objeto deste artigo. E isso porque ao mesmo tempo em que avança em determinados pontos referentes à autonomia dos povos indígenas, em diversos outros mantém uma postura mais conservadora, como na hipótese do item 2 , do art. $8^{\circ}$, do Texto, onde se estabelece que,

Esses povos deverão ter o direito de conservar seus costumes e instituições próprias, desde que eles não sejam incompatíveis com os direitos fundamentais definidos pelo sistema jurídico nacional nem com os direitos humanos internacionalmente reconhecidos. (...)

Percebe-se, pois, que o reconhecimento dos "costumes e instituições próprias dos povos" indígenas deve se dar "desde que eles não sejam incompatíveis com os direitos fundamentais definidos pelo sistema jurídico nacional nem com os direitos humanos internacionalmente reconhecidos", o que, deve-se ressaltar, constitui-se em medida arbitrária e antidemocrática, contrária ao próprio espírito da Convenção, posto ser sabido que os direitos fundamentais/humanos constituem, em boa medida, valores próprios da cultura européia moderna. Reconhecer a esses povos o direito ao reconhecimento de suas culturas e depois impor-lhes, pois é disso que se trata - imposição -, os direitos humanos, constitui medida, no mínimo, contraditória.

Valores como o respeito à natureza, solidariedade, fraternidade, cooperação e comunidade, por exemplo, que fazem partem de culturas indígenas a milhares de anos são estranhos ao nosso art. 5ำ (dispositivo que congrega os direitos e garantias fundamentais). Da mesma forma que valores como a propriedade privada e a herança, definidos no Brasil como direitos fundamentais, não compõem o imaginário dos povos indígenas; pelo menos não em sentido tão forte.

Isso apresenta-nos, no âmbito específico do direito, um problema de grande complexidade. Afinal, como conciliar um dispositivo constitucional que reconhece e assegura aos índios "sua organização social, costumes, línguas, crenças e tradições" com outros que pretendem o estabelecimento, como fundamentais, de institutos como a herança e a propriedade intelectual? 
Um dos âmbitos que fornecem interessantes subsídios para esse debate é o penal.

Em diversos trechos de seu texto, a Convenção reafirma a necessidade (obrigatoriedade) do respeito à identidade social e cultural, aos costumes e tradições, e às instituições das comunidades indígenas. Como, contudo, conciliar essa exigência, por exemplo, com o sistema penal vigente no Brasil? O crime nada mais é do que uma opção valorativa do legislador. Mas como trabalhar com o fato de que os valores europeus ocidentais e os valores adotados pelas comunidades indígenas não serem os mesmos?

Os artigos 8ำ 9e e 10 da Convenção trazem-nos questões interessantes no que tange à relação entre os direitos indígenas constitucionalmente reconhecidos ${ }^{2} \mathrm{e}$ a legislação penal ordinária:

\section{Artigo 8응}

1. Ao aplicar a legislação nacional aos povos interessados deverão ser levados na devida consideração seus costumes ou seu direito consuetudinário.

\section{Artigo 9을}

1. Na medida em que isso for compatível com o sistema jurídico nacional e com os direitos humanos internacionalmente reconhecidos, deverão ser respeitados os métodos aos quais os povos interessados recorrem tradicionalmente para a repressão dos delitos cometidos pelos seus membros.

2. As autoridades e os tribunais solicitados para se pronunciarem sobre questões penais deverão levar em conta os costumes dos povos mencionados a respeito do assunto.

2 Por direitos indígenas constitucionalmente reconhecidos entendemos não apenas aqueles do Capítulo VIII, do Título VIII, da Constituição Federal de 1988, mas igualmente as demais disposições constitucionais que se aplicam aos povos indígenas (como as referentes às suas terras) bem com as constantes da Convenção 169 da OIT, posto que, apesar da recepção infraconstitucional por meio do Decreto Legislativo no. 143 , de 20 de junho de 2002, entendemos que desde sua ratificação pelo Governo brasileiro, em razão do disposto no $\S^{\circ}{ }^{\circ}$, do art. $5^{\circ}$ da Constituição Federal, a Convenção integra o ordenamento constitucional brasileiro. 


\section{Artigo 10}

1. Quando sanções penais sejam impostas pela legislação geral a membros dos povos mencionados, deverão ser levadas em conta as suas características econômicas, sociais e culturais.

2. Dever-se-á dar preferência a tipos de punição outros que o encarceramento.

Da leitura desses artigos podemos extrair algumas questões de significativa complexidade. O que deve ser entendido por "ser levados na devida consideração seus costumes ou seu direito consuetudinário"? Ressalte-se que para os povos indígenas, o direito consuetudinário é o próprio direito. Então como conciliar a aplicação do ordenamento jurídico do 'homem branco' com as disposições (ainda que consuetudinárias) das legislações indígenas?

Percebe-se da leitura dos artigos acima, bem como das questões postas que a própria Convenção tem expressiva dificuldade em lidar com a questão. Percebe-se que no mesmo artigo em que garante 'força normativa' aos ordenamentos indígenas, (art. $8^{\circ}$, item 1) a Convenção titubeia e estabelece como limitador desses ordenamentos a compatibilidade "com os direitos fundamentais definidos pelo sistema jurídico nacional", bem como "com os direitos humanos internacionalmente reconhecidos".

Para acentuar ainda mais essas dificuldades, 0 art. 5o da Convenção estabelece que ao se aplicar os dispositivos convencionais: "a) deverão ser reconhecidos e protegidos os valores e práticas sociais, culturais religiosos e espirituais próprios dos povos mencionados (...)". E ainda: "b) deverá ser respeitada a integridade dos valores, práticas e instituições desses povos; (...)".

Na prática jurídica brasileira, como era de se esperar, essas dificuldades hermenêuticas vêm sendo decididas desfavoravelmente à causa indígena. Vejamos, por exemplo, o posicionamento de um dos mais respeitados juristas deste País e 
defensor dos direitos indígenas, Dalmo de Abreu Dallari, em debate sobre Direitos Indígenas ocorrido no Cebrap em 04 de junho de 2004:

O índio não tem privilégios: ele está sujeito à ação penal e está obrigado a respeitar a legislação inclusive em termos de conservação ambiental. (...) É preciso que o juiz pondere, em cada caso concreto, até que ponto o índio tinha consciência do significado jurídico e social do ato que praticou. Mas ele não é isento pelo fato de ser índio ${ }^{3}$.

Julgamos pertinente ressaltar que, num debate com especialistas em questões indígenas, realizado em junho de 2004, a Convenção 169 da OIT sequer é mencionada.

Não temos - a partir de uma leitura feita à luz dos direitos indígenas constitucionalmente reconhecidos - a mesma certeza que o prof. Dallari tem ao afirmar que o índio "está sujeito à ação penal e está obrigado a respeitar a legislação inclusive em termos de conservação ambiental". Concordamos que os índios não possuem privilégios, mas não podemos negar que possuem direitos. Como que o ordenamento constitucional brasileiro reconhece aos povos indígenas "sua organização social, costumes, línguas, crenças e tradições" e lhes impõe o ritual da ação penal? E se um índio derruba 1 (um) alqueire inteiro de uma árvore em extinção (o que configuraria crime ambiental), que para a tribo dele é maldita (ou algo assim)?

No mesmo debate, Paulo de Bessa Antunes, Procurador Regional da República no Rio de Janeiro, explica-nos que: "Havendo problemas entre os índios, o direito brasileiro reconhece a aplicação da legislação indígena naquilo que não contraria a lei nacional". E exemplifica: "se ocorre um problema dentro da sociedade indígena e o fato é punido com a pena de morte é preciso intervir, pois a legislação nacional não admite a pena de morte, salvo em caso de guerra"4.

E se a condenação à morte for para um índio de uma tribo inimiga capturado em uma guerra por território? É válida a decisão? Mais uma vez não temos nada dessa certeza. Não temos certeza - a partir de uma leitura feita à luz dos direitos indígenas constitucionalmente reconhecidos - de que "se ocorre um problema

3 DIREITOS INDíGENAS. Debate com Dalmo Dallari, Sérgio Leitão, Paulo de Bessa Antunes e Paula Montero. Debate realizado no Cebrap em 04 de junho de 2004. In: Novos Estudos, CEBRAP, no. 69, julho 2004, p. 66.

${ }^{4}$ Idem. 
dentro da sociedade indígena e o fato é punido com a pena de morte é preciso intervir".

Não podemos ler os direitos dos povos indígenas ao reconhecimento à luz de preconceitos e concepções ocidentais. Ao contrário, no que tange aos novos direitos, e em especial aos direitos indígenas, entendemos que o sistema jurídico brasileiro carece de uma nova hermenêutica, de uma forma plural e multicultural de compreender o fenômeno jurídico, forma essa que assegure aos povos indígenas os direitos que os ventos pós-88 Ihes trouxeram.

Em que pese, porém, todo esse reconhecimento, a prática judicial desenvolvida após 05 de outubro de 1988 em pouquíssimos casos tem acompanhado o "espírito" da Constituição ou, mais recentemente, da Convenção 169 da OIT. Não são raras decisões judiciais envolvendo direitos indígenas nas quais os textos constitucional e convencional sequer são mencionados.

No entanto, nem só de exemplos não-concretistas é composta a jurisprudência acerca dos direitos indígenas. Ao contrário, juristas existem que têm feito da concretização da Constituição Federal e da Convenção seus maiores objetivos. Alguns exemplos permitem-nos vislumbrar num futuro próximo, um Judiciário que trabalhe cotidianamente na realização da promessa constitucional de 1988.

\section{A PRÁtICA JURÍDICA EM QUESTÕES ENVOLVENDO DIREITOS INDÍGENAS NO PÓS-88.}

\subsection{Sobre a não-receptividade da Convenção na prática dos Tribunais}

É fato conhecido de todos que operam no âmbito do direito que o Judiciário brasileiro parece ter perdido, em algum momento longínquo, o trem da história. Tudo por aqui chega, quando chega, com espantoso atraso. Nosso Judiciário (em grande medida) parece desconhecer a promulgação de uma outra Constituição depois de 1967, insiste em ler o Estatuto do Índio (de 1973), não conhece a Convenção n.. 169 da OIT e parece que, no plano teórico, parou antes da Segunda Guerra. 
E na questão dos direitos indígenas, como era de se esperar, a questão é ainda mais grave. Exemplo flagrante disso é a decisão do STJ proferida em 05 de outubro de 2004 (coincidentemente quando a Constituição Federal de 1988 completava 16 anos) quando do julgamento do HC 30.113/MA. O habeas corpus visava a nulidade do processo, pela ausência de perícia antropológica e, subsidiariamente, à aplicação do disposto no art. 56, parágrafo único, da Lei n.. 6.001/73 (Estatuto do Índio). O paciente, índio Guajajara, havia sido condenado a 06 anos de reclusão e 08 meses de detenção. Nas razões recursais, a defesa sustentou, em síntese, a nulidade do processo, por falta de perícia antropológica, o que resultaria em cerceamento de defesa e, subsidiariamente, requereu a concessão do benefício do regime de semiliberdade, consoante disposto no art. 56 , parágrafo único, da Lei n. ${ }^{\circ}$ 6.001/73.

Nenhuma das teses da defesa logrou êxito perante o STJ. Em seu voto, o Ministro Relator, Gilson Dipp, afirmou que os dados constantes do processo eram suficientes para fornecer ao julgador todos os elementos necessário para a decisão do caso. Desconsiderou por completo o Ministro, a importância que possui o laudo pericial antropológico em processos judiciais em que são partes indígenas. A decisão, comparada a alguns artigos da Convenção n.. 169 da OIT - sequer mencionada no acordão -, não se sustenta.

Esse caso, aqui apenas brevemente mencionado, além de uma série de outros que poderíamos citar, demonstram a não-recepção por parte expressiva do Judiciário, dos direitos indígenas constitucionalmente reconhecidos, seja no âmbito da própria Constituição, seja no que diz respeito à Convenção n. 169 da OIT.

No entanto, casos existem que demonstram a possibilidade da construção de uma jurisprudência firme a favor da causa indígena, uma jurisprudência que, ao mesmo tempo em que assegura direitos aos povos indígenas, permite-lhes exercerem o seu próprio direito.

\subsection{Dois casos de concretização constitucional numa perspectiva plural, multicultural e de reconhecimento}

É sabido que as conquistas realizadas no âmbito legislativo nem sempre encontram paralelo no âmbito do Poder Judiciário. O casos mencionado na seção 
anterior exemplifica bem isso. No entanto, como já frisamos, nem só de exemplos não-concretistas é composta a jurisprudência pós-88 referente aos direitos indígenas, principalmente quando temos a presença constante e comprometida do Ministério Público Federal.

Os dois pareceres expostos e debatidos abaixo, de autoria do Procurador da República em Londrina/PR, João Akira Omoto, que gentilmente autorizou as citações, são de inegável caráter inovador e representam um alento para os povos indígenas brasileiros.

Os pareceres, em especial, chamam a atenção por duas razões: (a) a menção firme e constante ao art. 231, caput, da Constituição Federal e a dispositivos da Convenção 169 da OIT e (b) o reconhecimento do direito das comunidades indígenas envolvidas.

\subsubsection{O Estado de legítima defesa permanente}

O primeiro caso refere-se a um pedido de arquivamento do Inquérito $\mathrm{n}$. 227/2001 (Processo .. 2001.70.01.005471-1) perante a Subseção Judiciária Federal de Londrina/PR

A instauração do inquérito deu-se tendo em vista a ocorrência, em tese, do crime de homicídio (art. 121 do CP), que teria sido cometido por Reginaldo Salles Batarse e Josão Pereira da Silva, ambos indígenas. Segundo o apurado, em 16.11.1997, no Distrito de São João do Pinhal, município de São Jerônimo da Serra/PR, os acusados, mediante disparos com arma de fogo, causaram a morte de Adenílson da Silva Cruz.

Tendo em vista tratar-se de processo judicial envolvendo direitos indígenas, o Ministério Público Federal requereu a realização de perícia antropológica, o que de pronto foi autorizado pela Justiça Federal. E como era de se esperar, o laudo antropológico trouxe um novo desenho para o caso.

Na parte relativa ao mérito, após defender a competência da Justiça Federal para apreciar o caso, tendo em vista tratae-se de crime intimamente relacionado à disputa sobre terras indígenas (o que - ressalte-se - somente o laudo antropológico permitiu constatar), o parecer ministerial divide-se em duas partes, sendo uma sobre 
"O direito ao reconhecimento e a legislação aplicável aos povos indígenas" e outra que trata "Da legítima defesa".

Na primeira, o Ministério Público Federal apresenta ao Judiciário uma leitura ousada e atual da questão dos direitos indígenas. Com efeito, além da menção à indispensabilidade do laudo pericial antropológico, compõe a fundamentação do pedido de arquivamento os artigos 8ㄴ, 9ำ e 10 da Convenção n. 169 da OIT, bem como o Projeto de Declaração Americana sobre o Direito dos Povos Indígenas. Nessa primeira seção, conclui o parecer nos seguintes termos:

No presente caso, a somatória das informações trazidas pelo laudo pericial antropológico e do direito ao reconhecimento constituem pressupostos fundamentais para a caracterização do estado de legítima defesa permanente, sob o qual encontravam-se os acusados quando da ocorrência dos fatos.

Chama a atenção o fato de que, numa leitura formalista e nãoconcretizadora seria impossível falar de um estado de legítima defesa permanente, pois conforme dispõe o art. 25 do Código Penal, a caraterização da legítima defesa exige agressão injusta "atual ou iminente". Contudo, o parecer ministerial, fazendo uma leitura concretista e atual do sistema jurídico brasileiro, e fazendo amplo uso argumentativo do laudo pericial antropológico, conclui, citando o próprio laudo, que de forma categórica estabelece que os indiciados agiram em "situação de defesa e não de ataque".

Em linhas bem gerais, esse é o parecer do Ministério Público Federal concluído em 20 de janeiro de 2004 e que teve seus fundamentos como razões decisórias da Justiça Federal que, por sua vez, em 02.02.004 arquivou o inquérito.

\subsubsection{O direito do índio numa perspectiva multicultural e pluralista}

No outro exemplo, Olívio Guilherme e José Ekor Bonifácio, ambos indígenas, foram denunciados pelo Ministério Público Estadual de Londrina/PR como incursos nas penas dos art. 121, §2- I, c/c o art. 29, ambos do Código Penal (crime hediondo) por serem os responsáveis, em tese, pela morte do também indígena, João Dirceu Krigtánh Ribeiro. 
Em que pese tratar-se de processo em trâmite perante a justiça estadual, o Ministério Público Federal, na tentativa de auxiliar a resolução do caso, emitiu parecer dividido nas seguintes seções: "O direito que rege a matéria (reconhecimento)", "O aspecto antropológico e a necessidade de realização de laudo dessa natureza", "A especial proteção dos povos indígenas e o direito de permanecer detido na cadeia da Reserva Indígena".

Ao tratar do direito que rege a matéria, esclarece o Ministério Público Federal, acerca do teor do caput do art. 231 da Constituição Federal e do direito ao reconhecimento que tal dispositivo assegura.

No que tange ao laudo pericial antropológico, após defender sua necessidade em processos envolvendo indígenas, conclui recomendando ao Ministério Público Estadual que requisite ao Judiciário "para a realização de um julgamento constitucional, a elaboração de laudo pericial antropológico".

Por fim, ao defender a tese da especial proteção dos povos indígenas e o direito dos acusados de permanecerem detidos na cadeia da Reserva Indígena, argumenta o parecer que o caso exige o cumprimento dos "compromissos internacionais que o Estado brasileiro tem assumido de oferecer aos grupos vulneráveis, sobretudo aos indígenas, tratamento especializado".

Prosseguindo, esclarece o Ministério Público Federal acerca da recepção constitucional, pelo Brasil, da Convenção 169 da OIT, chamando a atenção, em especial, para os seguintes dispositivos legais:

Itens 1 e 2 , do art. $8^{\circ}$, segundo os quais:

1. Ao aplicar a legislação nacional aos povos interessados deverão ser levados na devida consideração seus costumes ou seu direito consuetudinário.

2. Esses povos deverão ter o direito de conservar seus costumes e instituições próprias, desde que eles não sejam incompatíveis com os direitos fundamentais definidos pelo sistema jurídico nacional nem com os direitos humanos internacionalmente reconhecidos. (...)

Itens 1 e 2 , do art. $9^{\circ}$, segundo os quais: 
1. Na medida em que isso for compatível com o sistema jurídico nacional e com os direitos humanos internacionalmente reconhecidos, deverão ser respeitados os métodos aos quais os povos interessados recorrem tradicionalmente para a repressão dos delitos cometidos pelos seus membros.

2. As autoridades e os tribunais solicitados para se pronunciarem sobre questões penais deverão levar em conta os costumes dos povos mencionados a respeito do assunto.

E, por fim, itens 1 e 2, do art. 10, segundo os quais:

1. Quando sanções penais sejam impostas pela legislação geral a membros dos povos mencionados, deverão ser levadas em conta as suas características econômicas, sociais e culturais.

2. Dever-se-á dar preferência a tipos de punição outros que o encarceramento.

Todas essas disposições são citadas para um precisa leitura da declaração prestada pelo Cacique da Reserva Indígena do Apucaraninha, Moisés Lourenço, em depoimento perante a Polícia Federal, onde afirma que:

(...) gostaria de destacar que a lei dos índios diz que, se o índio matar o próprio parente e a polícia o prender, o Cacique quiser tirar o índio de dentro da cadeia do branco, pode fazê-lo e prendê-lo dentro da reserva indígena.

Assim, segundo o parecer:

Vislumbra-se pela declaração que a Comunidade Indígena do Apucaraninha possui uma espécie de ordenamento jurídico próprio. Essas regras e noções de caráter sancionatório que fazem parte da Comunidade integram as expressões "organização social" e "costumes", ambas protegidas pelo art. 231 da Constituição Federal e pela Convenção n. 169 da OIT.

Assim, valendo-se das declarações prestadas pelo Cacique, de informações antropológicas e do todo o arsenal legislativo do qual o Brasil dispõe, conclui o parecer que, "tal comunidade indígena possui uma organização social de natureza 
sancionatória, a qual deve, em obediência aos textos citados, ser considerada tanto pelo Ministério Público, como pelo Judiciário". E finaliza:

Do exposto, tendo em vista o contido no art. 231, caput, da Constituição Federal de 1988, bem como o constante dos arts. $8^{\circ}$ a 10, da Convenção sobre os Povos Indígenas e Tribais em Países Independentes, entende o Ministério Público Federal que os acusados Olívio Guilherme e José Ekor Bonifácio devem ser transferidos para a Cadeia da Reserva Indígena do Apucaraninha, devendo a Fundação Nacional do Índio (Funai) comprometer-se a apresentar os acusados em juízo sempre que para tanto forem intimados.

Esse, portanto, o tratamento que entendemos deva ser dado no presente caso.

O parecer, encaminhado ao Ministério Público Estadual em setembro de 2003, foi inteiramente acatado tanto por sua destinatária, quanto pelo juiz responsável pelo caso, o que ocasionou o imediato requerimento de laudo pericial antropológico, bem como a transferência dos índios para a cadeia existente no interior da reserva onde habitam.

Esses dois casos mencionados dão-nos prova de que uma leitura pluralista e multicultural da Constituição Federal de 1988 é perfeitamente possível. E mais: permitem-nos vislumbrar num futuro próximo, um efetivo reconhecimento da cultura dos povos indígenas, um reconhecimento que permita aos povos indígenas regerem suas próprias relações sociais, voltando, de certo modo, a viver como viviam quando da chegada dos invasores.

\section{CONSIDERAÇÕES FINAIS}

Conforme vimos no decorrer do texto, as concepções pluralistas e multiculturais são fundamentais na compreensão dos direitos indígenas. E mais: somente podemos tentar compreender os direitos dos povos indígenas ao reconhecimento de suas culturas a partir de uma visão pluralista e multicultural. E necessário ter bem claro que "a uma sociedade que não é una, não pode corresponder um único Direito".

No plano jurídico, em particular, somente à luz da Constituição de 1988 e da Convenção $n .{ }^{\circ} 169$ da OIT podemos almejar uma correta aplicação do direito. 
No entanto, fica de fácil constatação que, mesmo no âmbito da Convenção, o direito dos povos indígenas de exercerem seu direito não se dá de forma plena. Nesse sentido, o item 2 do art. 8o é esclarecedor:

Esses povos deverão ter o direito de conservar seus costumes e instituições próprias, desde que eles não sejam incompatíveis com os direitos fundamentais definidos pelo sistema jurídico nacional nem com os direitos humanos internacionalmente reconhecidos. Sempre que for necessário, deverão ser estabelecidos procedimentos para se solucionar os conflitos que possam surgir na aplicação deste princípio.

Percebe-se claramente que mesmo aqui, naquela que pretende ser a Convenção dos Povos Indígenas, é muito forte a concepção ocidentalizada da supremacia do direito estatal e/ou dos direitos humanos. Aos povos indígenas fica assegurada a aplicação de seu direito consuetudinário, porém, desde que este seja conforme aos direitos humanos (ficção européia) e ao sistema jurídico do país onde a comunidade se encontra. Pode uma comunidade ser autônoma, ter sua cultura, organização social, crenças, tradições e costumes reconhecidos sem que se garanta conjuntamente o poder de regular suas relações por meio do direito? Não. Há autonomia com imposição de uma concepção valorativa? De modo algum.

Disso decorre a necessidade de uma leitura constitucional da Convenção, posto que o art. 231 da Constituição brasileira é claro ao reconhecer "aos índios sua organização social, costumes, línguas, crenças e tradições", independentemente de qualquer restrição. E ao reconhecer a organização social, os costumes, as crenças e as tradições desses povos, a Constituição Federal assegura o reconhecimento de seu direito. Assegura tanto a liberdade de produzi-lo, quando a autonomia em aplicá-lo.

Somente essa leitura garante significado à disposição constitucional e se coaduna com uma perspectiva multicultural e pluralista de reconhecimento. Dessa forma, afigura-se imperioso reconhecer que - nos limites da reserva - são os povos indígenas soberanos. O reconhecimento garante que, nas questões internas, à comunidade cabe resolver as questões controversas, mesmo que nesse processo haja violação de qualquer norma do sistema jurídico brasileiro.

Já nas questões que envolvam indígenas e não-indígenas permite-se a atuação do Estado. Contudo, mesmo aqui, a ingerência deve se dar de modo a respeitar costumes, línguas, crenças e tradições dos povos indígenas, fato que, por 
exemplo, torna nulidade insanável a ausência de laudo pericial antropológico em causa na qual seja parte um índio ou uma comunidade indígena.

Ademais, julgamos como indispensável para uma efetiva concretização dos direitos indígenas constitucionalmente reconhecidos, o debate do direito com outros ramos do saber, em especial, a história, a sociologia e a antropologia. Faz-se necessário que o direito abra-se para outros saberes, para novos desafios, pois somente assim restaram vencedores aqueles que lutam por um direito plural e multicultural.

Tudo isso, sem dúvida, contribuirá para que um dia torne-se claro no imaginário social que:

Los pueblos indígenas tienen derecho a conservar y reforzar sus propias características políticas, económicas, sociales y culturales, así como sus sistemas jurídicos, manteniendo a la vez sus derechos a participar plenamente, si lo desean, en la vida política, económica, social y cultural del Estado (Artigo $4^{\circ}$ do Projeto de Declaração sobre os Direitos das Populações Indígenas da ONU).

\section{REFERÊNCIAS BIBLIOGRÁFICAS}

ALBUQUERQUE, Antônio Armando Ulian do Lago. Multiculturalismo e o Direito à Autodeterminação dos Povos Indígenas. Orientação de Thaís Luzia Colaço. Florianópolis, 2003, Dissertação de Mestrado, Universidade Federal de Santa Catarina. Centro de Ciências Jurídicas.

BÁRCENAS, Francisco López. Legislación y Derechos Indígenas en México. México, 2002.

BOFF, Leonardo. Nova Era: a civilização planetária. São Paulo: Editora Ática, 2000.

BORRERO, Camilo. A Pluralidade como Direito, in Qual Direito? Seminários N. 16. Rio de Janeiro: AJUP/FASE, 1991.

BOTERO, Esther Sánchez, JARAMILLO SIERRA, Isabel Cristina. La Jurisdición Especial Indígena. Bogotá: Imprenta Nacional de Colombia y Procuraduría Delegada Asuntos Etnicos, 2000.

CIFUENTES, José Emilio Ordoñez. El sistema jurídico indígena en el marco del pluralismo jurídico, in I Conferencia Nacional sobre Derechos Humanos, Guatemala, 16 - 18 abril, 2002. Informe editado por ASIES. Guatemala, 2002, pp. 117-132.

DIREITOS INDÍGENAS. Debate com Dalmo Dallari, Sérgio Leitão, Paulo de Bessa Antunes e Paula Montero. Debate realizado no Cebrap em 04 de junho de 2004. In: Novos Estudos, CEBRAP, №. 69, julho 2004. 
KYMLICKA, Will. Ciudadanía Multicultural. Una teoría liberal de los derechos de las minorias. Traducción de Carme Castells Auleda. Cubierta de Victor Viano. Barcelona: Ediciones Paidós Ibérica S.A., 1996.

MALDI, Denise. et. al. (org). Direitos Indígenas e Antropologia: laudos periciais em Mato Grosso. Cuiabá : Editora Universitária da UFMT, 1994.

PAPADÓPOLO, Midori. El Nuevo Enfoque Internacional en Materia de Derechos de los Pueblos Indígenas. Guatemala: Universidad Rafael Landívar, Instituto de Investigaciones Económicas y Sociales, 1995.

TORRE RANGEL, Jesus Antônio de la. Pluralismo Jurídico enquanto Fundamentação para a Autonomia Indígena, in: WOLKMER, Antônio Carlos (org.). Direitos Humanos e Filosofia Jurídica na América Latina. Rio de Janeiro: Editora Lumen luris, 2004, pp. 311-326.

SANTILLI, Juliana (coord.). Os Direitos Indígenas e a Constituição. Porto Alegre: Safe, 1993.

SANTOS, Sílvio Coelho dos (org.). O Índio Perante o Direito (Ensaios). Florianópolis: Ed. da UFSC, 1982.

SOUZA, Álvaro Reinaldo de. Os Povos Indígenas: minorias étnicas e a eficácia dos direitos constitucionais no Brasil. Orientação de Edmundo Lima de Arruda Jr. Florianópolis, 2002, Tese de Doutorado. Universidade Federal de Santa Catarina. Centro de Ciências Jurídicas, TOMO I.

SOUZA FILHO, Carlos Frederico Marés de. O Renascer dos Povos para o Direito. Orientação de Clèmerson Merlin Clêve. Curitiba, 1998. Tese de Doutorado. Universidade Federal do Paraná. Curso de Pós-Graduação em Direito, Setor de Ciências Jurídicas.

WOLKMER, Antônio Carlos. Pluralidade Jurídica na América Luso-Hispânica, in Direito e Justiça na América Indígena. WOLKMER, Antônio Carlos (org.). Porto Alegre: Livraria do Advogado, 1998, pp. 75-93.

Pluralismo Jurídico. Fundamentos de uma nova cultura no Direito. 3. ed. rev. e atual. São Paulo: Editora Alfa Ômega, 2001. 